\title{
Full-Factorial Experimental Design to Determine the Impacts of Influential Parameters on the Porosity and Mechanical Strength of LLDEP Microporous Membrane Fabricated via Thermally Induced Phase Separation Method
}

\author{
Elham Shokri ${ }^{1,2}$ and Reza Yegani ${ }^{1,2, *}$ \\ ${ }^{1}$ Faculty of Chemical Engineering, Sahand University of Technology, Sahand New Town, Post Box: \\ 51335/1996, Tabriz, Iran \\ ${ }^{2}$ Membrane Technology Research Center, Sahand University of Technology, Sahand New Town, Post Box: \\ 51335/1996y, Tabriz, Iran
}

\begin{abstract}
Membrane separation processes have a wide application in liquid and gas purification industries. They enjoy advantages such as convenient processibility, easy and lower production and operational costs. Thermally induced phase separation (TIPS) process, due to its wide advantages, has won special attention in recent decades. In this process, a homogenous solution of polymer-diluent at a temperature above the polymer melting point is formed and the solution is then cast in the favorite shape. In order to create a porous structure, the diluent is extracted. In this work, microporous LLDPE membrane is fabricated and full factorial experimental design is used to evaluate the individual as well as mutual impacts of polymer concentration, membrane thickness and cooling bath temperature on the porosity and mechanical strength of the membrane. The results obtained from the analysis of variance of membrane porosity and mechanical strength, showed that the impact of cooling bath temperature is much more important than polymer concentration and membrane thickness. Higher cooling bath temperature, lower polymer concentration and membrane thickness result in higher porosity.
\end{abstract}

Keywords: Thermally induced phase separation (TIPD), Design of experiments (DOE), Linear low density polyethylene (LLDPE), Porosity, Mechanical strength.

\section{INTRODUCTION}

The application of Membrane Separation Technology (MST) has grown significantly in recent years. Membranes are mainly utilized in microfiltration (MF), ultrafiltration (UF), reverse osmosis (RO) and gas separation. The most important part of each application is the membrane itself. Before any action, a membrane of appropriate material and structure needs to be selected for separation. In microfiltration and ultrafiltration, the porosity as well as the pore size determine the membrane performance. Porosity is a main feature of the membrane even in gas separation processes in which a dense and non-porous selective layer in the outer surface overlies the porous supporting layer [1-4]. Mechanical strength is another important response to characterize the membrane structure.

There are several methods to fabricate porous membrane. Depending on the type of polymer, the required porosity, mechanical strength and the availability of fabrication technology a proper method can be selected. Fabrication methods include thermal

*Address corresponding to this author at the Membrane Technology Research Center, Sahand University of Technology, Sahand New Town, Post Box: 51335/1996y, Tabriz, Iran; Tel: (0098) 412345-9147; Fax: (0098) 412344-4355;

E-mail: ryegani@sut.ac.ir sintering, track etching, stretching and phase separation [5]. However, phase separation is a conventional process in the fabrication of polymeric membranes in which a homogenous solution of polymer, diluent and any other additives is converted into the lean and rich phases of the polymer. The polymer-rich phase forms the polymeric matrix of the membrane where polymer-lean phase forms the membrane pores.

In the thermally induced phase separation, depending on the condition and mixture composition, a homogenous solution is formed and by altering temperature, phase separation occurs. Given the conditions of formation of homogenous solution, this method is carried out in the form of vapor induced phase separation, non-solvent induced phase separation and thermally induced phase separation [2, $6,7]$.

Since this research is done based on the thermally induced phase separation; a homogenous polymerdiluent solution in a temperature above the polymer's melting point is formed. Then, the temperature is decreased for the system to be destabilized and phase separation would occur. The most important advantage of TIPS method is the lifting of restrictions to the selection of the proper solvent for polymer [8-10]. 
Depending on the percentage of polymer in the blend, TIPS can proceed via two-phase separation mechanisms, liquid-liquid or solid-liquid phase separations. In liquid-liquid phase separation, when the temperature declines, two phases including polymerlean and polymer-rich phases are formed and by solidifying the rich phase, the main structure of the membrane takes shape. In solid-liquid phase separation, a non-homogenous solution is born out of polymer crystals to give solid and liquid phases. The final structure of membrane heavily depends on the polymer properties and crystallization conditions.

TIPS method makes it possible to fabricate membrane using semi-crystalline and thermoplastic polymers such as polyolefines, copolymers and polymer blends.

In order to modify the structural and operational properties of membrane, various membranes using polystyrene [11], polysulfon [12], cellulose acetate [1314], polypropylene [15-18, 19-24], polyvinylidene fluoride (PVDF) [25-27], high density polyethylene [28, 29], polymer blends [25-27] have been fabricated by TIPS method.

Various parameters such as thermodynamic factors, crystallization kinetics, diluent specifications e.g. crystallization temperature, mobility and molecular weight [26-32], solution viscosity [3], molecular weight distribution, polymer hydrophilicity [37] or hydrophobicity [38], cooling conditions [39, 40] and the existence of nucleation agents [41] have been studied in order to find out the structural specifications of the membrane.

Numerous studies have been conducted on the effect of influential parameters like polymer concentration and cooling bath temperature on the porosity and mechanical strength; however, no accurate study is available regarding the mutual impacts of these parameters and the significance of influential factors. The design of experiment is a branch of knowledge helping to measure the impact of influential factors $\left(X_{1}, X_{2}, X_{3}, \ldots\right)$ on the outputs $\left(Y_{1}, Y_{2}\right.$, $\left.Y_{3}, \ldots\right)$ under $Y_{i}=F\left(X_{i}\right)$ equation [42]. The objectives behind the design of experiments include minimizing the number of tests, saving time and costs, determining significant variables or specifying optimal conditions. Analysis of the results should also determine their reliability. For this purpose the compatibility analysis was applied.
In order to determine the components of the table of analysis of variance, variables such as, degree of freedom for each factor $\left(D_{f}\right)$, sum of squares $(S)$ mean squares $(V)$, variance ratio $(F)$ and contribution ratio $(P)$ were calculated using minitab14 software. The calculated variables are shown in Table 2.

In this article, the level of porosity and mechanical strength of fabricated polymeric membrane were measured and the impacts of parameters such as polymer concentration, cooling bath temperature and membrane thickness were analyzed.

\section{EXPERIMENTAL}

\subsection{Materials}

Linear Low Density Polyethylene (LLDPE) (MFI=1) as polymer from Tabriz Petrochemical Company, mineral oil as diluent $\left(\rho=0.851 \mathrm{~g} / \mathrm{cm}^{3}\right)$ from Acros, and ethanol as extractant from Merck were purchased. All chemical and reagents were used with no more treatment, unless otherwise described.

\subsection{Membrane Fabrication}

A specific amount of polymer and mineral oil were mixed in the overhead mixer and the temperature was raised to Above the melting point of polymer $\left(185^{\circ} \mathrm{C}\right)$ in order to have a homogenous mixture. After releasing the bubbles, a portion of the achieved solution is poured onto a flat plate glass and spread out using a casting knife. The glass plate containing polymeric solution was then immersed in a water bath for phase separation. After detaching from the surface of the plate, the membrane was put into ethanol for 6 hours until its diluent is fully extracted. Finally, it was held in the room temperature for 24 hours so that the ethanol would be completely removed.

\subsection{Porosity Measurement}

The fabricated membrane is weighed in a digital balance before being dipped into isobutanol for 24 hours. The membrane is weighed immediately after being taken out of isobutanol. The porosity of the membrane is calculated through the following equation [41]:

$$
\varepsilon=\frac{\left(\mathrm{w}_{\mathrm{w}}-\mathrm{w}_{\mathrm{d}}\right) / \rho_{\mathrm{w}}}{\left(\mathrm{w}_{\mathrm{w}}-\mathrm{w}_{\mathrm{d}}\right) / \rho_{\mathrm{w}}+\left(\mathrm{w}_{\mathrm{d}} / \rho_{\mathrm{\rho}}\right.} \times 100
$$


Table 1. Experimental Factors and Levels Envestigated on the Porosity and Mechanical Strength of Membrane

\begin{tabular}{|c|c|c|}
\hline Factor & Parameter levels & Parameter values \\
\hline \hline A: Polymer concentration $(w t)$ & 2 & 25,30 \\
\hline B: Cooling bath temperature $\left({ }^{\circ} \mathrm{C}\right)$ & 3 & $0,30,60$ \\
\hline C: Film thickness $(\mu \mathrm{m})$ & 2 & 250,500 \\
\hline
\end{tabular}

Where $w_{w}$ is the mass of wet membrane in $g r, w_{d}$ is the mass of dry membrane in $\mathrm{gr}, \rho_{\mathrm{w}}$ and $\rho_{\rho}$ are the density of isobutanol and polyethylene in $\left(\mathrm{gr} / \mathrm{cm}^{3}\right)$, respectively.

\subsection{Membrane Strength}

The tensile strength of the membranes was measured using a SANTAM STM-5 tensile testing instrument for all samples according to ASTM D-638 at crosshead speed of $50 \mathrm{~mm} / \mathrm{min}$. The thickness of flat membranes was measured using micrometer. Each sample was clamped at the both ends with an initial gauge length of $50 \mathrm{~mm}$ and width of $10 \mathrm{~mm}$. Three trials were performed per each sample and the mean value was reported for all samples.

\subsection{Experimental Design}

In the design of experiments, the impact of polymer concentration, cooling bath temperature and membrane thickness on the porosity and mechanical strength of polyethylene membrane were evaluated. Table 1 lists the variables and levels. All factors were examined in various levels and experiments were conducted twice to minimize errors. A total of 24 experiments were conducted.

\section{Table 2: Analysis of Variance for $Y$ (Membrane Porosity)}

\begin{tabular}{|c|c|c|c|c|c|}
\hline Impact & $D_{f}$ & S & v & $\mathbf{F}$ & $\mathbf{P}$ \\
\hline$A$ & 1 & 160.17 & 160.17 & 21.84 & 0.001 \\
\hline$C$ & 1 & 322.67 & 322.67 & 44 & 0.000 \\
\hline$A^{*} B$ & 2 & 3.58 & 1.79 & 0.24 & 0.787 \\
\hline $\mathrm{B}^{*} \mathrm{C}$ & 2 & 163 & 81.54 & 11.12 & 0.002 \\
\hline$A^{*} B^{*} C$ & 2 & 2.25 & 1.13 & 0.15 & 0.859 \\
\hline Error & 23 & 88 & 7.33 & ------ & ----- \\
\hline Total & 47 & 3746.33 & ------ & ------ & ----- \\
\hline
\end{tabular}

Table 3: Analysis of Variance for $Y$ (Membrane Mechanical Strength)

\begin{tabular}{|c|c|c|c|c|c|}
\hline Impact & $D_{f}$ & $S$ & V & $\mathbf{F}$ & $\mathbf{P}$ \\
\hline A & 1 & 2.535 & 2.535 & 21.73 & 0.001 \\
\hline C & 1 & 1.251 & 1.251 & 10.73 & 0.004 \\
\hline$A^{*} B$ & 2 & 0.134 & 0.067 & 0.58 & 0.577 \\
\hline $\mathrm{B}^{*} \mathrm{C}$ & 2 & 0.618 & 0.309 & 2.65 & 0.111 \\
\hline$A^{*} B^{*} C$ & 2 & 0.015 & 0.007 & 0.06 & 0.939 \\
\hline Error & 12 & 1.460 & 0.117 & ------ & ------ \\
\hline Total & 23 & 16.660 & ------ & ------ & ------ \\
\hline
\end{tabular}




\section{RESULTS AND DISCUSSION}

\subsection{Results of Analysis of Variances (ANOVA)}

Table 2 and 3 show the data obtained from the analysis of variance on the porosity and mechanical strength of fabricated LLDPE membrane. The results show that all three parameters including cooling bath temperature, polymer concentration and membrane thickness are effective in membrane porosity and mechanical strength because their P-values are lower than 0.005 . Comparing the variances ratios, it is concluded that cooling bath temperature is the most influential one owing to its higher F-value. The membrane thickness and polymer concentration, the interaction between the bath temperature and the polymer thickness come next in membrane porosity. In the case of mechanical strength the impact of polymer concentration is more important than film thickness and the effect of interactional parameters is negligible.

\subsection{Individual Impacts of Parameters}

The individual impacts of all three influential parameters in full factorial design of experiments are shown in Figure 1. The membrane porosity was selected as the response function.
As shown in Figure 1, when polymer concentration and membrane thickness increase from 25 to $30 \%$ (w/w) and 250 to $500 \mu \mathrm{m}$, respectively, the porosity decreases smoothly. However, the effect of cooling bath temperature on the porosity is much steeper.

Figure 2 illustrates the individual impacts of three mentioned parameters on the mechanical strength of membrane. The trend of mechanical strength is inversely proportional to porosity. The individual impacts of these parameters on the membrane porosity and mechanical strength will be discussed in the following sections.

\subsubsection{Impact of Cooling Bath Temperature}

The results from the variance analysis of porosity show that the cooling bath temperature is the most influential parameter on the membrane porosity and mechanical strength. Its P-value is less than 0.005 and F-value is maximal.

In the thermally induced phase separation, since the bath temperature makes the homogenous polymer system unstable, increasing the cooling rate of the polymer solution affects the final structure of the membrane. In the liquid-liquid phase separation, the cooler the polymer solution, the more time the polymer-

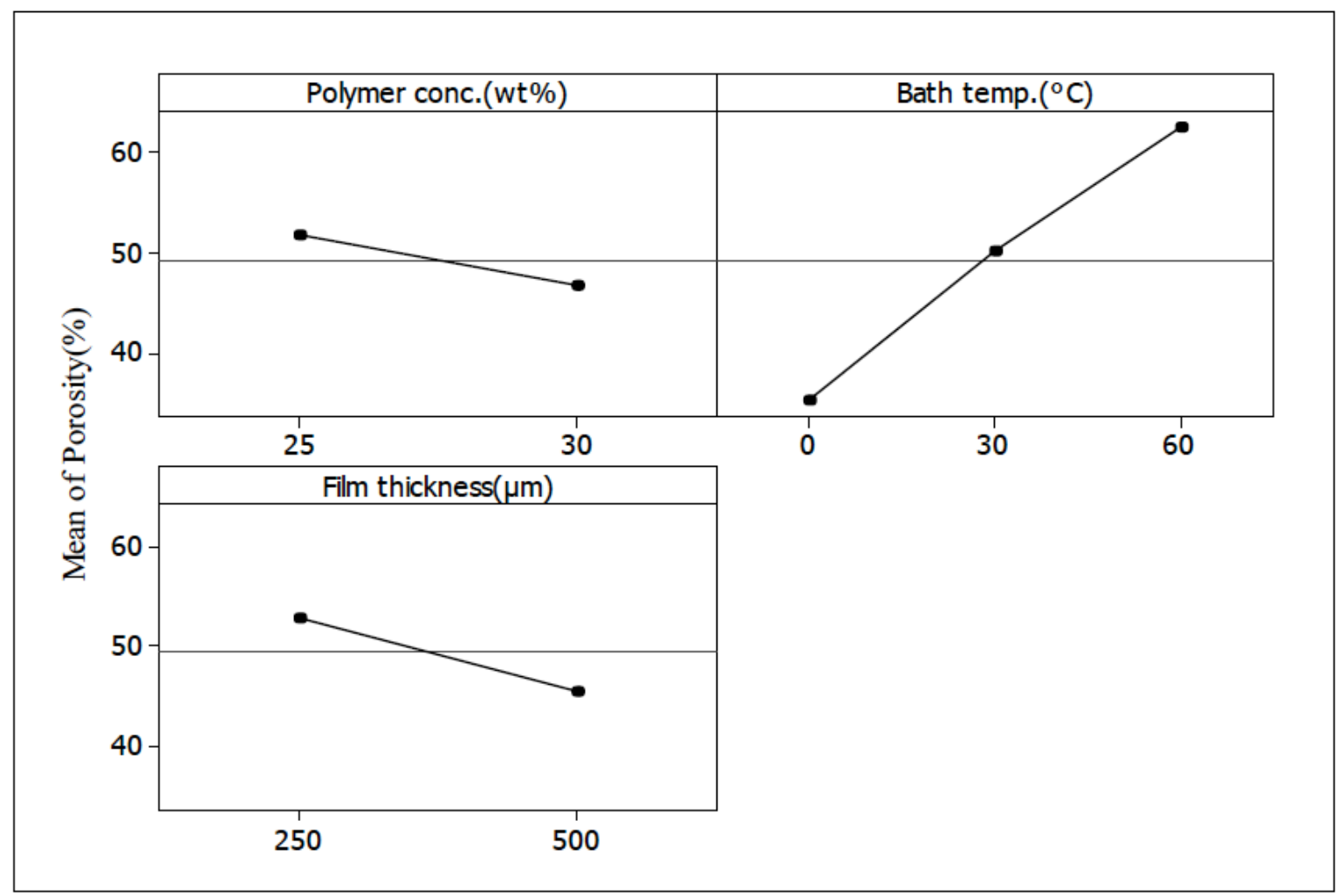

Figure 1: The individual impacts of polymer concentration, cooling bath temperature and polymer film thickness in full factorial design of experiments on membrane porosity. 


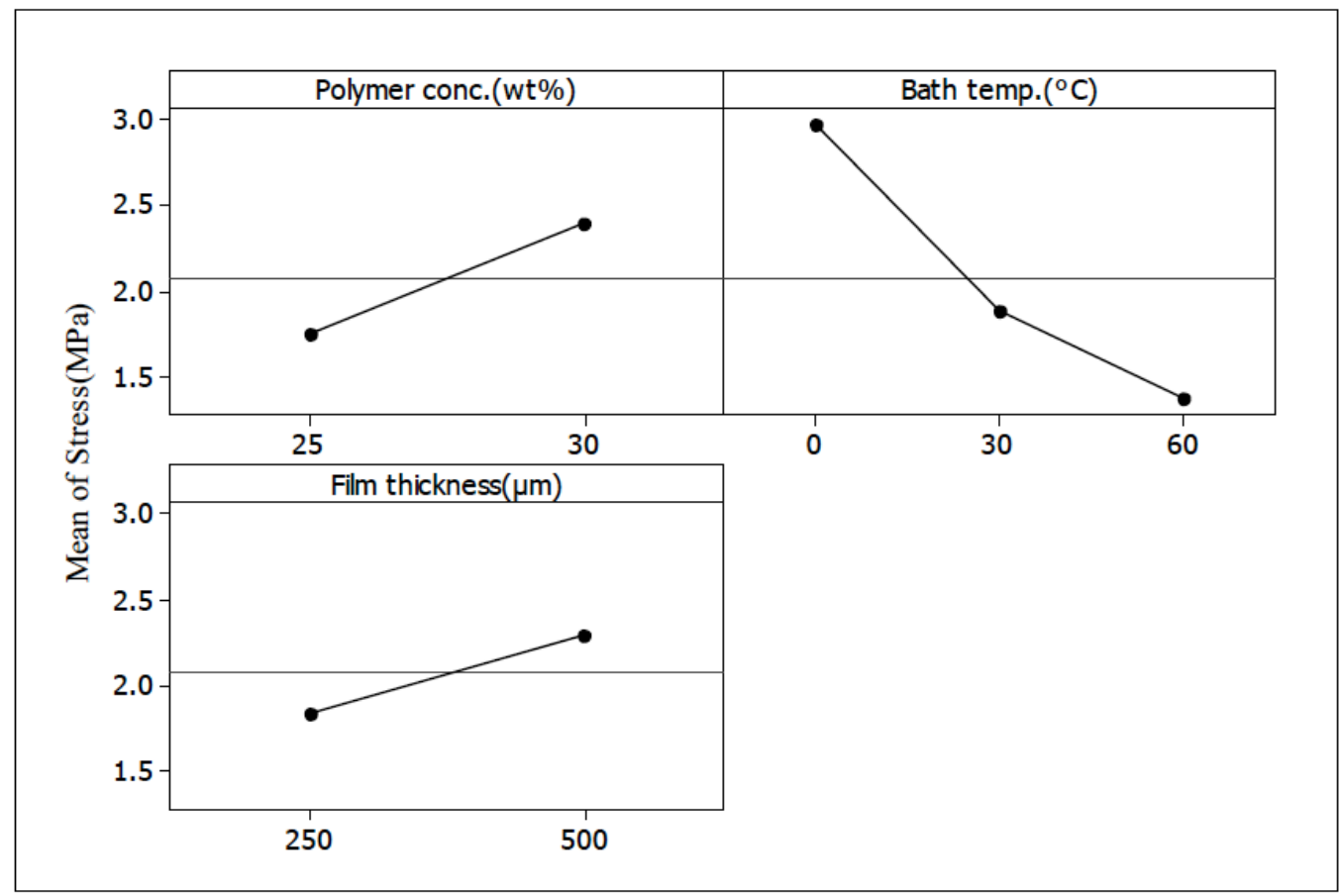

Figure 2: The individual impacts of polymer concentration, cooling bath temperature and polymer film thickness in full factorial design of experiments on membrane mechanical strength.

lean phase would have to grow and the membrane porosity increases and mechanical strength decreases. In solid-liquid phase separation, with lower cooling rate of polymer solution, spherulites get longer time to grow and the voids between pores increases resulting in bigger porosity.

Figure 3 shows the cross-sectional images of LLDPE membrane when the polymer concentration and membrane thickness were fixed at $25 \%(\mathrm{w} / \mathrm{w})$, and $500 \mu \mathrm{m}$, respectively and cooling bath temperature varies between 0 and $60^{\circ} \mathrm{C}$. SEM images show interconnected structure of pores. As shown in Figure 3, the pore size in higher bath temperature is bigger than that when bath temperature is low. When the cooling bath temperature is fixed at $60{ }^{\circ} \mathrm{C}$, due to lower cooling rate of polymer solution, solidification occurs slowly and pores get enough time to grow. The result would be larger pores.

The images show quite well that the variation of cooling bath temperature results in bigger changes in the membrane porosity.

\subsubsection{Impact of Membrane Thickness}

The results obtained from Table 2 and 3 indicate that the membrane thickness affects the membrane porosity and mechanical strength. As shown in Figure
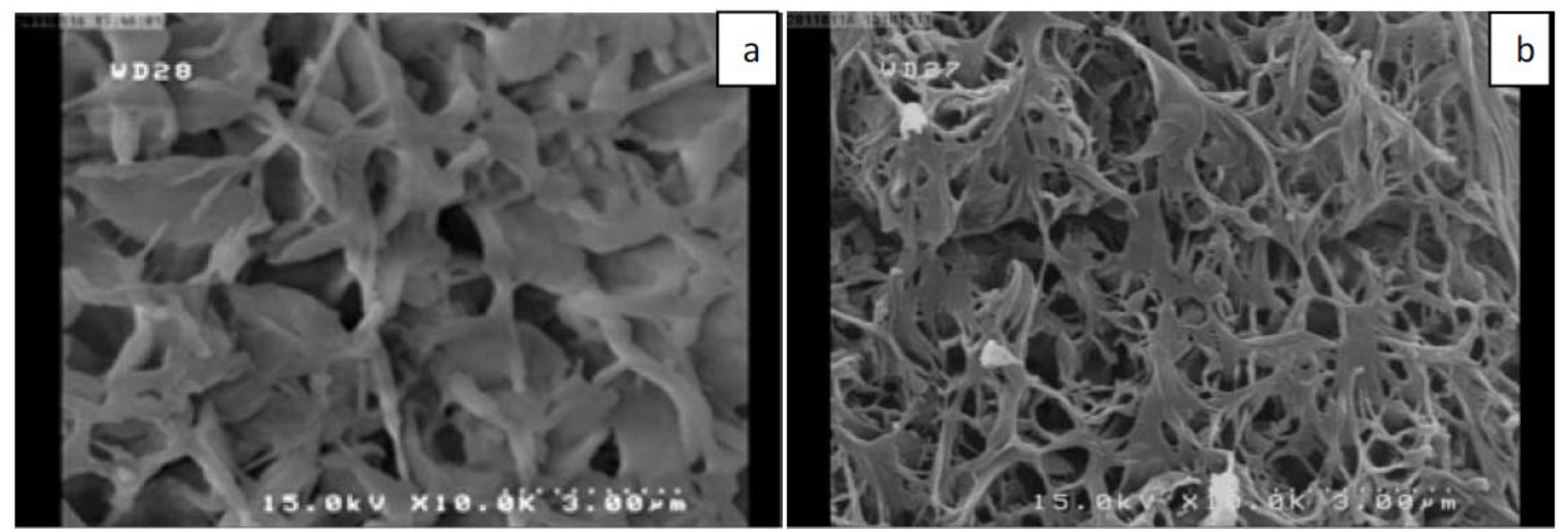

Figure 3: Cross-sections SEM images of LLDPE membranes fabricated with a polymer concentration of 25 wt $\%$, film thickness of $500 \mu \mathrm{m}$ in different cooling bath temperature, (a) $0{ }^{\circ} \mathrm{C}$ and (b) $60{ }^{\circ} \mathrm{C}$. 
1, any increase in the membrane thickness, decreases the membrane porosity. Figure 2 shows that increasing the film thickness cause to decrease the membrane mechanical strength. Although there are no reports about the impact of membrane thickness on the membrane structure, one can simply conclude that the membrane thickness affects the exit rate of diluent from the membrane network before solidification.

In thicker membranes, during the phase separation occurring in defined time intervals, the diluent will not have enough time to completely exit from the membrane porous network and the result would be lower porosity. On the other hand, the existence of diluent in polymer matrix increases the density of nucleation sites, and it results, to lower porosity. Since the membrane thickness and cooling bath temperature affect each other, their mutual impacts will be discussed in the following paragraphs.

\subsubsection{Impact of Polymer Concentration}

In order to evaluate the impact of polymer concentration on the membrane structure, two polymer concentrations; 25 and $30 \%(\mathrm{w} / \mathrm{w})$ were selected and membranes were fabricated. The results in the table of data variance analysis of porosity show that increasing the polymer concentration from 25 to $30 \%(\mathrm{w} / \mathrm{w})$ slightly affects the membrane porosity and mechanical strength.

Several published works have certified the great influence of polymer concentration on the membrane porosity. In solid-liquid phase separation, an increase in the polymer concentration raises the number of spherolites and lower porosity is achieved. In liquidliquid phase separation, increasing the polymer concentration decreases the volume fraction of polymer-lean phase and higher mechanical strength is finally achieved.

Comparing the obtained results with the reported data reveals that when polymer concentration does not alter the mechanism of phase separation, it will have fewer effects than cooling bath temperature on membrane porosity and mechanical strength. It is the point which has not been explained in the previously published articles.

\subsection{Mutual Impacts of Influential Parameters}

Figure 4 shows the mutual impacts of influential parameters on membrane porosity in examined levels. Results are obtained using miniab14 software. In mutual interactions of thickness-polymer concentration and cooling bath temperature-polymer concentration,

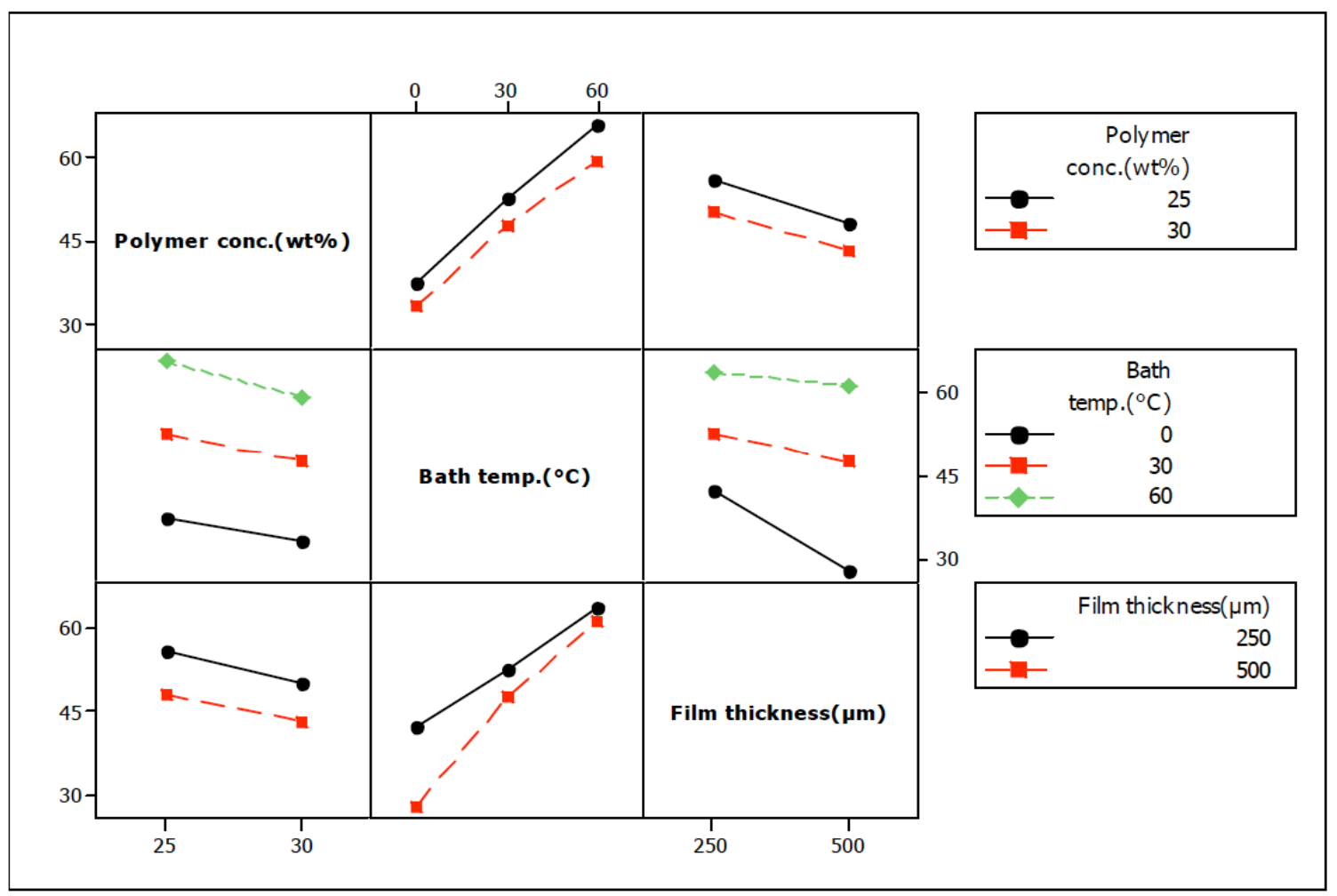

Figure 4: The mutual impacts of polymer concentration, cooling bath temperature and polymer film thickness in full factorial design of experiments on membrane porosity. 
since the curves are quite far from each other, their mutual interactions are negligible. In the curve of polymer concentration-cooling bath temperature obtained at $60{ }^{\circ} \mathrm{C}$, two curves get quite close to each other and the obtained porosity is about $60 \%$.

When the cooling bath temperature is fixed at $0{ }^{\circ} \mathrm{C}$, changing the membrane thickness from 500 to $250 \mu \mathrm{m}$ increases the membrane porosity while increasing the cooling bath temperature, the impact of membrane thickness declines. When the cooling bath temperature is fixed at $60{ }^{\circ} \mathrm{C}$, increasing the membrane thickness shows no significant impact on the membrane porosity.

This issue could be justified by the impact of cooling bath temperature. The polymer solution temperature falls as it enters the cooling bath for phase separation, which would take place more easily in lower thicknesses due to easy heat transfer when polymer is getting hard. The phase separation easily takes places and pores get enough time to grow, and higher porosity is achieved.

When the cooling bath temperature is fixed at $0{ }^{\circ} \mathrm{C}$, due to the faster phase separation, membrane thickness plays the main role; however, in higher bath temperatures, since there is enough time for phase separation, even in higher membrane thicknesses, the diluent would have enough time to leave the membrane porous network and pores become larger. Therefore at higher bath temperatures, membranes with higher thicknesses show similar porosity with the membranes having lower thickness.

Figure 5 shows the interaction of parameters in membrane mechanical strength. Since there are no connections between curves, it is possible to say that the mutual interaction between parameters on the mechanical strength is still negligible. However, similar to membrane porosity, at higher bath temperatures, membranes with higher thicknesses show similar mechanical strength with the membranes having lower thickness. These results confirm the important role of cooling bath temperature on the porosity and mechanical strength of membrane.

\section{CONCLUSION}

In order to fabricate membrane with defined porosity and mechanical strength, the impact of three influential parameters, namely, polymer concentration, cooling bath temperature and membrane thickness were evaluated. Polymer concentration in two levels, 20 and $30 \%(w / w)$, cooling bath temperature in three levels, 0 ,

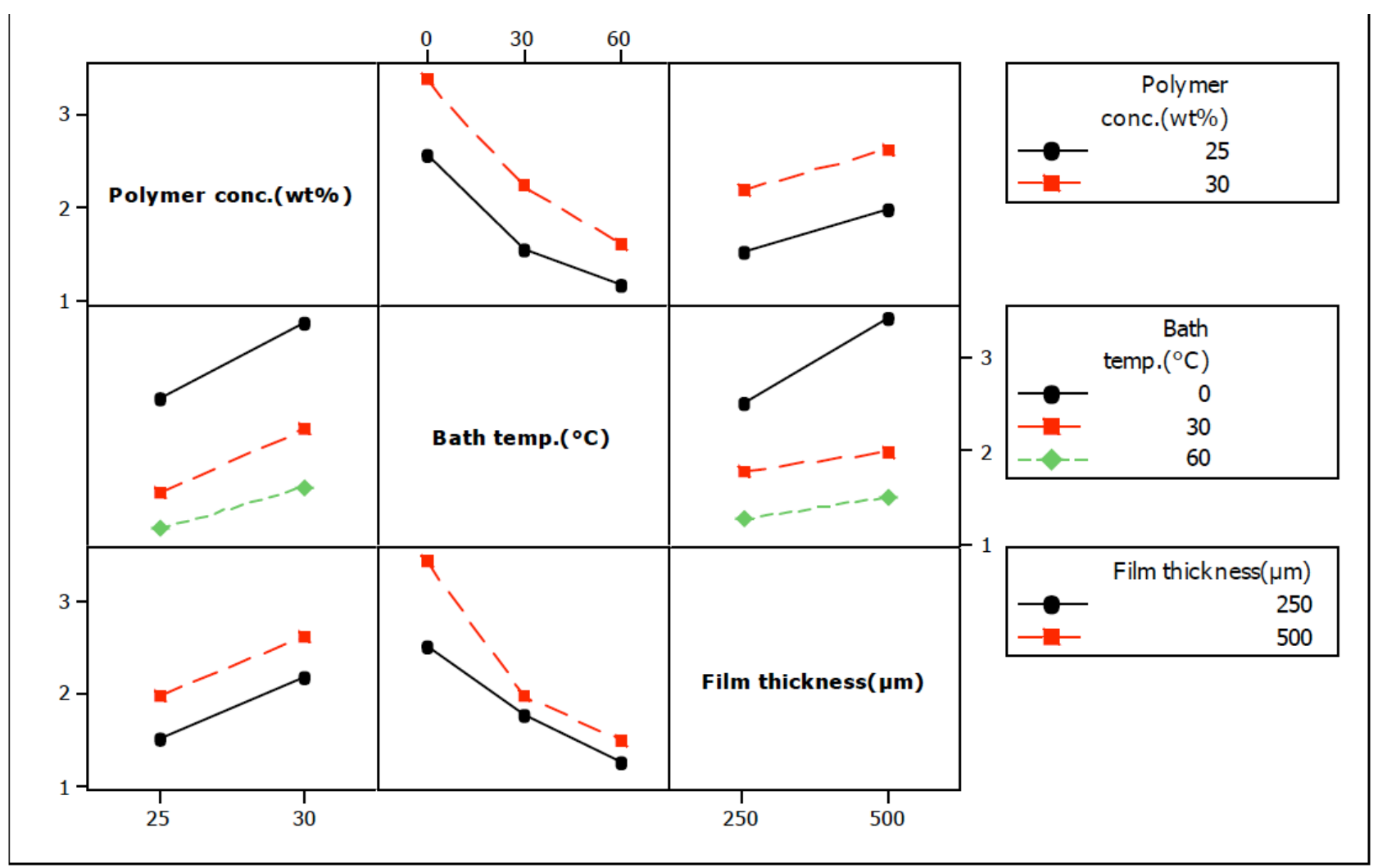

Figure 5: The mutual impacts of polymer concentration, cooling bath temperature and polymer film thickness in full factorial design of experiments on membrane mechanical strength. 
30 and $60{ }^{\circ} \mathrm{C}$ and membrane thickness in two levels, 250 and $500 \mu \mathrm{m}$, were used and the impact as well as the order of magnitude on each parameters on the membrane response were determined.

The table of analysis of variance showed that cooling bath temperature is instrumental and in the defined domains of membrane thickness and polymer concentration, the impact of polymer concentration and membrane thickness were similar. The curves show the individual as well as the mutual impacts of influential parameters. It is also shown that membrane porosity increases when the bath temperature decreases and membrane thickness increases. The trend of mechanical strength is inversely proportional to membrane porosity. Due to the mutual impact of higher bath temperatures and membrane thicknesses in membrane porosity, the obtained porosity at $60{ }^{\circ} \mathrm{C}$ for both membrane thicknesses is similar. It was revealed that, the impact of polymer concentration on the porosity remains negligible, if it cannot alter the mechanism of phase separation. It is also concluded that cooling bath temperature can hinders the impact of other influential parameters such as membrane porosity and mechanical strength.

\section{REFERENCES}

[1] Mulder M. Basic principles of membrane technology. $2^{\text {nd }}$ ed. Kluwer academic publishers: Netherlands 1996. http://dx.doi.org/10.1007/978-94-009-1766-8

[2] Witte P, Dijkstra PJ, Berg JW, Feijen J. Phase separation processes in polymer solutions in relation to membrane formation. J Membr Sci 1996; 117: 1-31. http://dx.doi.org/10.1016/0376-7388(96)00088-9

[3] Tsai F, Torkelson J. Microporous Poly(methyl methacrylate) Membranes: Effect of a Low-Viscosity Solvent on the Formation Mechanism. J Macromol 1990; 23: 4983-9. http://dx.doi.org/10.1021/ma00225a018

[4] Pusch W, Walch A. Synthetic membranes preparation, structure and application. J GDCH 2003; 21(9): 660-85.

[5] Drioli E, Criscuoli A, Curcio E. Membrane contactors: fundamentals, applications and potentialities. $1^{\text {st }}$ ed. elsevier: Netherlands 2006.

[6] Lloyd R, Kim SS, Kinzer KE. Microporous membrane formation via thermally induced phase separation, II. Liquidliquid phase separation. J Membr Sci1991; 64: 1-11. http://dx.doi.org/10.1016/0376-7388(91)80073-F

[7] Nunes SP, Peinemann V. Membrane technology in the chemical industry, Wiley-VCH 2001. http://dx.doi.org/10.1002/3527600388

[8] Sarif M, Mohd A. Development of the integrally skinned polysulfone ultrafiltration membrane: effect of casting parameters. PhD thesis, Universiti Sains Malaysia 2005.

[9] Lloyd R. Microporous membrane formation via thermally induced phase separation.solid-liquid phase separation. $\mathrm{J}$ Membr Sci1990; 52: 239-61. http://dx.doi.org/10.1016/S0376-7388(00)85130-3

[10] Castro AJ. Methods for making microporous products in US Patent. 42474981981.
Song SW, Torkelson JM. Coarsening effects on the formation of microporous membranes produced via thermally induced phase separation of polystyrene-cyclohexanol solutions. J Membr Sci 1995; 98: 209-22.

http://dx.doi.org/10.1016/0376-7388(94)00189-6

[12] Tsai HA, Kuo CY, Lin JH, et al. Morphology control of polysulfone hollow fiber membranes via water vapor induced phase separation. J Membr Sci 2006; 278(1-2): 390-400. http://dx.doi.org/10.1016/j.memsci.2005.11.029

[13] Matsuyama H, Ohga K, Maki T, Teramoto M, Nakatsuka S. Porous cellulose acetate membrane prepared by thermally induced phase separation. J Poly Sci 2003; 89(14): 3951-55.

[14] Lima JA, Felisberti MI. Porous polymer structures obtained via the TIPS process from EVOH/PMMA/DMF solutions. J Membr Sci 2009; 344(1-2): 237-43. http://dx.doi.org/10.1016/j.memsci.2009.08.008

[15] Kim SS, Lloyd R. Microporous membrane formation via thermally induced phase separation. III. Effect of thermodynamic interactions on the structure of isotactic polypropylene membranes. J Membr Sci 1991; 64: 13-29. http://dx.doi.org/10.1016/0376-7388(91)80074-G

[16] Kim SS, Gordon BA, Alwattari AA, Wang YF, Lloyd R. Microporous membrane formation via thermally induced phase separation. V. Effect of diluent mobility and crystallization on the structure of isotactic polypropylene membranes. J Membr Sci 1991; 64: 41-53. http://dx.doi.org/10.1016/0376-7388(91)80076-I

[17] Lim BA, Kim SS, Ye Q, Wang YF, Lloyd R, Microporous membrane formation via thermally induced phase separation. IV. Effect of isotactic polypropylene crystallization kinetics on membrane structure. J Membr Sci 1991; 64: 31-40. http://dx.doi.org/10.1016/0376-7388(91)80075-H

[18] Lin YK, Chen G, Yang J, Wang XL. Formation of isotactic polypropylene membranes with bicontinuous structure and good strength via thermally induced phase separation method. Desalination 2009; 236(1-3): 8-15. http://dx.doi.org/10.1016/j.desal.2007.10.044

[19] Luo B, Li Z, Zhang J, Wang X. Formation of anisotropic microporous isotactic polypropylene (iPP) membrane via thermally induced phase separation. Desalination 2008; 233(1-3): 19-31.

http://dx.doi.org/10.1016/j.desal.2007.09.023

[20] Alwattari AA, Lloyd R. Microporous membrane formation via thermally induced phase separation. VI. Effect of diluent morphology and relative crystallization kinetics on polypropylene membrane structure. J Membr Sci 1991; 64: 55-68. http://dx.doi.org/10.1016/0376-7388(91)80077-J

[21] Yang ZS, Li PL, Xie LX, Wang Z, Wang SC. Preparation of iPP hollow-fiber microporous membranes via thermally induced phase separation with co-solvents of DBP and DOP. Desalination 2006; 192: 168-81. http://dx.doi.org/10.1016/j.desal.2005.10.016

[22] Yave W, Quijad R, Serafini D. Effect of the polypropylene type on polymer-diluent phase diagrams and membrane structure in membranes formed via the TIPS process: Part I. Metallocene and Ziegler-Natta polypropylenes. J Membr Sci 2005; 263(1-2): 146-53.

http://dx.doi.org/10.1016/j.memsci.2005.04.043

[23] Matsuyama $\mathrm{H}$, Maki $\mathrm{T}$, Teramoto M, Asono K. Effect of polypropylene molecular weight on porous membrane formation by thermally induced phase separation. J Membr Sci 2002; 204(1-2): 323-8. http://dx.doi.org/10.1016/S0376-7388(02)00056-X

[24] Matsuyama H, Yuasa M, Kitamura Y, Teramoto M, Lloyd R. Structure control of anisotropic and asymmetric polypropylene membrane prepared by thermally induced phase separation. J Membr Sci 2000; 179(1-2): 91-100. http://dx.doi.org/10.1016/S0376-7388(00)00506-8 
[25] Gu M, Zhang J, Wang X, Tao H, Ge L. Formation of poly (vinylidene fluoride) (PVDF) membranes via thermally induced phase separation. Desalination 2006; 192(1-3): 1607.

http://dx.doi.org/10.1016/j.desal.2005.10.015

[26] Cui ZY, Xu YY, Zhu LP, Wang JY, Xi ZY, Zhu BK. Preparation of PVDF/PEO-PPO-PEO blend microporous membranes for lithium ion batteries via thermally induced phase separation process. J Membr Sci 2008; 325(2): 95763.

http://dx.doi.org/10.1016/..memsci.2008.09.022

[27] Rajabzadeh S, Maruyama T, Ohmukari Y, Sotani T, Matsuyama $\mathrm{H}$. Preparation of PVDF/PMMA blend hollow fiber membrane via thermally induced phase separation (TIPS) method. Sep Purif Technol 2009; 66(1): 76-83. http://dx.doi.org/10.1016/j.seppur.2008.11.021

[28] Matsuyama $\mathrm{H}$, Okafuji $\mathrm{H}$, Maki T, Teramoto M, Kubota N. Preparation of polyethylene hollow fiber membrane via thermally induced phase separation. J Membr Sci 2003; 223(1-2): 119-26.

http://dx.doi.org/10.1016/S0376-7388(03)00314-4

[29] Zhang C, Bai Y, Sun Y, Gu J, Xu Y. Preparation of hydrophilic HDPE porous membranes via thermally induced phase separation by blending of amphiphilic PE-b-PEG copolymer. J Membr Sci 2010; 365(1-2): 216-24. http://dx.doi.org/10.1016/j.memsci.2010.09.007

[30] Qiu YR, Rahman NA, Matsuyama H. Preparation of hydrophilic poly(vinyl butyral)/Pluronic F127 blend hollow fiber membrane via thermally induced phase separation. Sep Purif Technol 2008; 61(1): 1-8. http://dx.doi.org/10.1016/j.seppur.2007.09.014

[31] Roh IJ, Ramaswang S, Krantz WB, Greenberg AR. Poly(ethylene chlorotrifluoroethylene) membrane formation via thermally induced phase separation (TIPS). J Membr Sci 2010; 362(1-2): 211-20. http://dx.doi.org/10.1016/j.memsci.2010.06.042

[32] Qiu Y, Hideto M, Zhong H, Ye H, Huang K. Effects of diluent molecular weight on the performance of hydrophilic poly(vinyl butyral)/Pluronic F127 blend hollow fiber membrane via thermally induced phase separation. J Membr Sci 2009; (21)338: $128-34$.

[33] Cha IJ, Char K, Kim JJ. The effect of diluent molecular weight on the structure of thermally induced phase separation membrane. J Membr Sci 1995; 108: 219-29. http://dx.doi.org/10.1016/0376-7388(95)00171-9
[34] Yang Z, Li P, Chang H, Wang S. Effect of diluent on the morphology and performance of IPP hollow fiber microporous membrane via thermally induced phase separation. J Chin Chem Eng 2006; 14(3): 394-7. http://dx.doi.org/10.1016/S1004-9541(06)60089-X

[35] Zhang J, Fu J, Wang X, Wang B, Xu Z, Wen J. Effect of diluents on hydrophilic ethylene-acrylic acid co-polymer membrane structure via thermally induced phase separation. Desalination 2006; 192(1-3): 151-9.

http://dx.doi.org/10.1016/..desal.2005.10.014

[36] Qu YR, Matsuyama H. Preparation and characterization of poly(vinyl butyral) hollow fiber membrane via thermally induced phase separation with diluent polyethylene glycol 200. Desalination 2010; 257(1-3): 117-23. http://dx.doi.org/10.1016/j.desal.2010.02.036

[37] Fu X, Matsuyama H, Teramato M, Nagai H. Preparation of hydrophilic poly(vinyl butyral) hollow fiber membrane via thermally induced phase separation. Sep Purif Technol 2005; 45(3): 200-7. http://dx.doi.org/10.1016/j.seppur.2005.04.012

[38] Tang N, Jia Q, Zhang H, Li J, Cao S. Preparation and morphological characterization of narrow pore size distributed polypropylene hydrophobic membranes for vacuum membrane distillation via thermally induced phase separation. Desalination 2010; 256(1-3): 27-36. http://dx.doi.org/10.1016/j.desal.2010.02.024

[39] Shang M, Matsuyama H, Teramoto M, Lloyd R, Kubota N. Effect of glycerol content in cooling bath on performance of poly(ethylene-co-vinyl alcohol) hollow fiber membranes. Sep Purif Technol 2005; 45(3): 208-12. http://dx.doi.org/10.1016/j.seppur.2005.04.013

[40] Zhou J, Zhang H, Wang H, Du Q. Effect of cooling baths on EVOH microporous membrane structures in thermally induced phase separation. J Membr Sci 2009; 343(1-2): 1049. http://dx.doi.org/10.1016/j.memsci.2009.07.029

[41] Luo B, Zhang J, Wang X, Zhou Y, Wen J. Effects of nucleating agents and extractants on the structure of polypropylene microporous membranes via thermally induced phase separation. Desalination 2006; 192(1-3): 14250.

http://dx.doi.org/10.1016/j.desal.2005.10.013

[42] Montgomery DC. Design and Analysis of Experiments, John Wiley \& Sons Australia, Limited 1999. 